\title{
Evaluation of the Contralateral Acoustic Stimulation Test After Audiological Examination of the Central Auditory System in Individuals with Normal Hearing
}

\author{
Sercan CAN YILDIZ \\ Department of Audiology, Turgut Özal University Health School, Ankara, Turkey \\ E-mail: selcanyildizxp@hotmail.com \\ Mustafa YÜKSEL \\ Department of Audiology, Turgut Özal University Health School, Ankara, Turkey \\ E-mail: yukselphysics@gmail.com \\ Fatma MEN KILINÇ (Corresponding Author) \\ Department of Audiology, Turgut Özal University Health School, Ankara, Turkey \\ E-mail: fatmamen.61@gmail.com
}

\begin{abstract}
The aim of our study was to evaluate the contralateral acoustic stimulation tests of central auditory system after audiological examination of individuals with normal hearing. In this context, a number of criteria were considered for the determination of individuals with normal hearing.

Normal hearing provides the ability to live independently in the social environment of an individual, and the level of hearing is considered necessary for enabling communication with the environment. A total of 15 individuals were included in our study. In all individuals, five different frequencies were obtained compared to the threshold for both ears. The frequencies were $1000 \mathrm{~Hz}, 1414 \mathrm{~Hz}, 2000 \mathrm{~Hz}, 2828 \mathrm{~Hz}$ and $4000 \mathrm{~Hz}$; and the suppression thresholds were also measured. After audiological tests were performed for our study, the same measurements were repeated. Looking at the results of the study, a statistically significant difference was found between the measurement results for right and left ears in individuals with normal hearing $(\mathrm{P}<0.05)$.

Result: In order to see the suppressive effect, the integrity of the neural structures must be preserved starting from the medial nucleus of the superior olivary complex and reaching the OHCs. According to the results obtained in our study, we can conclude that MOCR is active, and the central nervous system is not impaired after the audiological evaluation. However, it is thought that a further study should be conducted with a larger sample group in order to obtain more specific results.
\end{abstract}

Keywords: Contralateral suppression, normal hearing, otoacoustic emissions

DOI: $10.7176 / \mathrm{JHMN} / 87-06$

Publication date:March $31^{\text {st }} 2021$

\section{Introduction}

Hearing is very important for individual development and interpersonal communication. Any impairment in the auditory system results in social isolation by affecting language development, academic achievement and mental development negatively.

Otoacoustic emissions (OAE) are sounds generated by the outer hair cells of the cochlea, which can be measured with the aid of a microphone placed in the external auditory canal (D. T. Kemp, 1978). The decrease in the emission responses in the ear, which are measured by sending loud noise to the contralateral ear, indicates the presence of the medial olivocochlear (MOC) reflex (Smith \& Cone, 2015). The MOC reflex allows us to adapt to this noise by reducing the response of our auditory system towards a continuous noise, and to adapt our dynamic hearing range to the existing environmental conditions. Contralateral medial olivocochlear system (MOCS) efferents have a direct impact on the function of outer hair cells. In adults with normal hearing, contralateral noise increases the speech intelligibility due to the MOC reflex activated by exposure to the loud noise (Smith $\&$ Cone, 2015). 
Some of the current audio-vestibular test batteries operate by sending a high intensity sound stimulus. In the descending method, which is used for determining the hearing thresholds during audiological evaluation, highfrequency pure tones can be used starting from loud noise in order to find the threshold. Considering that all frequencies are evaluated in this method, the individual can be exposed to loud sounds for a minimum of 20 minutes. In addition,

pure sounds above $80 \mathrm{~dB}$, which are sent during both tympanometry and acoustic reflex measurement, can damage OHCs, albeit temporarily; however it is not possible to detect them. In the other hand, it has been argued that the pure tones used as $100 \mathrm{~dB}$ nHL in VEMP tests, a part of the vestibular test battery, can cause more damage to OHCs compared to what is estimated(ER TOPRAK, 2016). Considering the impact of the efferent system to increase the signal by suppressing the noise, it is possible that this system, which is directly related to OHCs, may be affected by a destruction in OHCs (Smith \& Cone, 2015).

In our study, we aimed to observe the effects of these tests on the auditory efferent system by measuring contralateral suppression before and after audiovestibular tests.

\section{Materials and Method}

This study was conducted in the audiology and speech disorders clinic in a local university hospital, department of ear, nose and throat diseases. The compliance of the study with ethical and scientific principles was unanimously agreed by clinical research ethics committee of the local hospital with the Decision Number 99950669/112.

After obtaining approval of the ethics committee approval and the written informed consent form from the volunteers, the study was conducted with 15 male and voluntary participants between 18 and 36 years of age (mean 23. $2 \pm 3.91$ years). Among the volunteers, individuals with normal hearing, who did not have any systemic disease according to the otoscopic examination and audiological evaluation, who did not use ototoxic drugs, who did not have any problems regarding exposure to noise, and who did not have a medical history of ear diseases, were included in the study. Individuals, who did not have any complaints such as restriction of neck joint movements, dizziness, tinnitus, fullness, nausea and vomiting were included in the vestibular examination group. All participants of the study were asked to sign the "Voluntary Participation (Informed Consent) Form".

\subsection{Research Protocol}

Audiological evaluation was performed to all participants of the study. In the audiological evaluation performed prior to the vestibular tests, immitansmetric and pure tone audiometric measurements were made. Transient Evoked Otoacoustic Emission (TEOAE) values were evaluated in the absence and presence of suppression. The entire test protocol was repeated at every stage before and after audiological and vestibular evaluation.

\subsubsection{Immitansmetric Measurements}

Middle ear pressures, ipsilateral and contralateral stapes reflex thresholds were assessed between the range of 0.5 and $4 \mathrm{kHz}$ at the probe tone of $226 \mathrm{~Hz}$ and $85 \mathrm{~dB}$ SPL using the Interacoustics AT235H device. In the automated evaluation, the type with the peak curve of "Type A" in the pressure range of $+200 \mathrm{daPa}$ and $-400 \mathrm{daPa}$ was considered as a normal tympanogram.

\subsubsection{Pure Tone Audiometry}

The sample of the study was determined with an emphasis on the criterion that the participants were individuals with normal hearing. Therefore, the normality of hearing was evaluated in all individuals. Pure tone audiometry (Interacoustic AC 40 Clinical Audiometry, Denmark) was used in the audiological evaluation, and the evaluations were performed according to ANSI standards, following audiometric evaluation procedures and in a standard soundproof booth. Pure tone audiometric evaluations of the airway were performed in the range of 0.25 and $8 \mathrm{kHz}$ with Telephonic TDH-39 (Telephonics, USA) headphones, and bone conduction evaluations were performed in the range of 0.5 and $4 \mathrm{kHz}$ using a Radioear B-71 (Radioear, USA) bone vibrator.

Participants with a bilateral hearing ability at $20 \mathrm{~dB}$ HL and below, active stapes reflexes and "Type A" curves in tympanogram, were considered to have normal hearing.

\subsubsection{Speech Tests}

The second stage of audiological evaluation involves speech recognition and speech discrimination. Human voice is used as a stimulus. It consists of a list of words previously recorded or read by the specialist. The patients are asked to repeat the words they hear in order to understand how they recognize speech. This evaluation method provides useful information in the diagnosis of middle ear, cochlear and retrocochlear pathology. 


\subsubsection{Measurement of TEOAE and Contralateral Suppression}

Binaural measurement of TEOAE was performed using

the ILO 292 Echoport USB II and ILO V6 Clinical OAE software (Otodynamics, London) device. Suppression test was performed when the SNR ratio was $3 \mathrm{~dB}$ and above, and the repeatability rate was $85 \%$. Linear-click stimulus was used, and the measurements were recorded in a mean of 260 times at a speed of $50 / \mathrm{s}$ and $57 \mathrm{~dB}$ SPL in the $80 \mu \mathrm{sec}$ stimulus mode. Thresholds $(1000 \mathrm{~Hz}, 1414 \mathrm{~Hz}, 2000 \mathrm{~Hz}, 2828 \mathrm{~Hz}, 4000 \mathrm{~Hz})$ and total SNR (Signal-to-Noise Ratio) values obtained with each stimulus were used as the parameters of the study. TEOAE and suppression values in both ears were found to be normal in the participants of the study, and Transient Evoked Otoacoustic Emission (TEOAE) measurements were repeated in the absence and presence of contralateral stimuli.

After the measurement of TEOAE, the measurement was repeated for contralateral suppression without removing the probe from the ear, which was performed by sending white noise at $60 \mathrm{~dB}$ SPL from the Interacoustics-Clinical Audiometer AC33 device to the opposite ear with insert earphones, in a quiet booth.

The signal and SNR suppression values were calculated by subtracting the responses during noise and TEOAE responses before the noise was sent. It is expected that there will be a decrease in the TEOAE values obtained before exposure to the noise (before suppression). A lower value in frequencies compared to the previous values means suppression is achieved. In all measurements, TEOAE and contralateral suppression tests were performed for both ears, respectively. Later, the same procedures were administered for the other ear in the same order. The differences between the suppression amplitudes of the values obtained in the presence and absence of the contralateral stimulus were calculated.

\subsubsection{Vestibular Evaluation}

C-VEMP measurements were performed using the Otometrics ICS Chartr EP 200 device. VEMP recordings were the responses obtained by the contraction of the SCM after rotating the individual in the supine position with the head 30 degrees above the stimulated side. They were measured using ER3A (Etymotic Research Inc, Illinois, USA) insert headphones with a $500 \mathrm{~Hz}$ tone burst stimulus. Measurements were performed with $10 \mathrm{~dB}$ attenuation until the first positive wave (P1) and the following negative wave (N1) after the stimulus was sent, starting from $100 \mathrm{~dB} \mathrm{nHL}$ intensity. The measurements were limited to 200 stimuli at 4 stimulation rates per second. Self-adhesive single patient surface electrode was used during the test; and the electrode impedance was adjusted to less than $5 \mathrm{kohm}$ (ER TOPRAK, 2016).

\subsection{Statistics}

Under each heading, Descriptive statistics were calculated, graphic charts were created, and statistical tests were performed. In order to test the assumptions for parametric tests, the number of participants in the groups were checked, and the data were analyzed for normality. There were 15 participants in both groups, and the data were tested for normality using the Kolmogorow-Smirnov Test. As a result of the normality test, the data were observed to have normal distribution $(\mathrm{p}>0.05)$. Therefore, although the data had normal distribution, the assumptions for parametric tests were not met due to the number of individuals in the groups, which was below 30 .

\section{Results}

Wilcoxon signed-rank test was used for evaluating the threshold values of the right ear before and after the audiological test. Minimum, maximum, mean and standard deviation values were calculated for the threshold values before and after the test.

Table 1: Suppression Values of the Right Ear

\begin{tabular}{lllll}
$\begin{array}{l}\text { Frequency } \\
\text { Value }\end{array}$ & $\begin{array}{l}\text { Before the Audiology Test } \\
\text { Mean } \pm \text { sd (Min - Max) }\end{array}$ & $\begin{array}{l}\text { After the Audiology Test } \\
\text { Mean } \pm \text { sd (Min - Max) }\end{array}$ & $\begin{array}{l}\text { Difference } \\
\text { (Before - After) }\end{array}$ & $\begin{array}{l}\text { Test** } \\
\text { p Value }\end{array}$ \\
\hline $\mathbf{1 0 0 0 ~ H z}$ & $9.03 \pm 7.49(-6.20-21.60)$ & $8.35 \pm 6.89(-4.80-21.10)$ & $0.68 \mathrm{~dB}$ & 0.460 \\
$\mathbf{1 4 1 4} \mathbf{~ H z}$ & $12.95 \pm 6.16(2.50-24.20)$ & $8.70 \pm 7.45(-3.80-18.50)$ & $4.25 \mathrm{~dB}$ & $\mathbf{0 . 0 0 4 *}$ \\
$\mathbf{2 0 0 0 ~} \mathbf{~ H z}$ & $11.66 \pm 6.39(2.70-23.10)$ & $8.95 \pm 5.97(-1.10-17.90)$ & $2.71 \mathrm{~dB}$ & $\mathbf{0 . 0 0 5 *}$ \\
$\mathbf{2 8 2 8} \mathbf{~ H z}$ & $7.49 \pm 7.10(-3.40-23.10)$ & $5.72 \pm 6.26(-5.00-13.90)$ & $1.77 \mathrm{~dB}$ & 0.222 \\
$\mathbf{4 0 0 0 ~} \mathbf{~ H z}$ & $4.77 \pm 6.70(-5.10-19.20)$ & $3.26 \pm 5.76(-6.60-17.90)$ & $1.51 \mathrm{~dB}$ & 0.061 \\
\hline
\end{tabular}

sd: standard deviation; Min: lowest frequency value; Max: Highest Frequency value; **: Wilcoxon Signed-Rank Test; ${ }^{*} \mathrm{p}<0.05$ : There is a statistically significant difference between measurements. 
In the right ear, there was a decrease in the mean threshold values at frequencies of $1000 \mathrm{~Hz}, 2828 \mathrm{~Hz}$ and 4000 $\mathrm{Hz}$ after the audiological test. The changes in the mean threshold values at frequencies of $1000 \mathrm{~Hz}, 2828 \mathrm{~Hz}$ and $4000 \mathrm{~Hz}$ in the right ear were not found to be statistically significant ( $\mathrm{p}>0.05$, Table 1$)$.

In the right ear, mean threshold values at frequencies of $1414 \mathrm{~Hz}$ and $2000 \mathrm{~Hz}$ decreased after the audiological test. The changes in the mean threshold values in the right ear at frequencies of $1414 \mathrm{~Hz}$ and $2000 \mathrm{~Hz}$ were found to be statistically significant $(\mathrm{p}<0.05$, Table 1$)$.

The chart below displays the mean threshold values of the right ear. Frequency values are presented horizontally, and the mean threshold values are presented vertically. The orange line indicates the values before the audiological test, and the green line indicates the values after the audiological test.

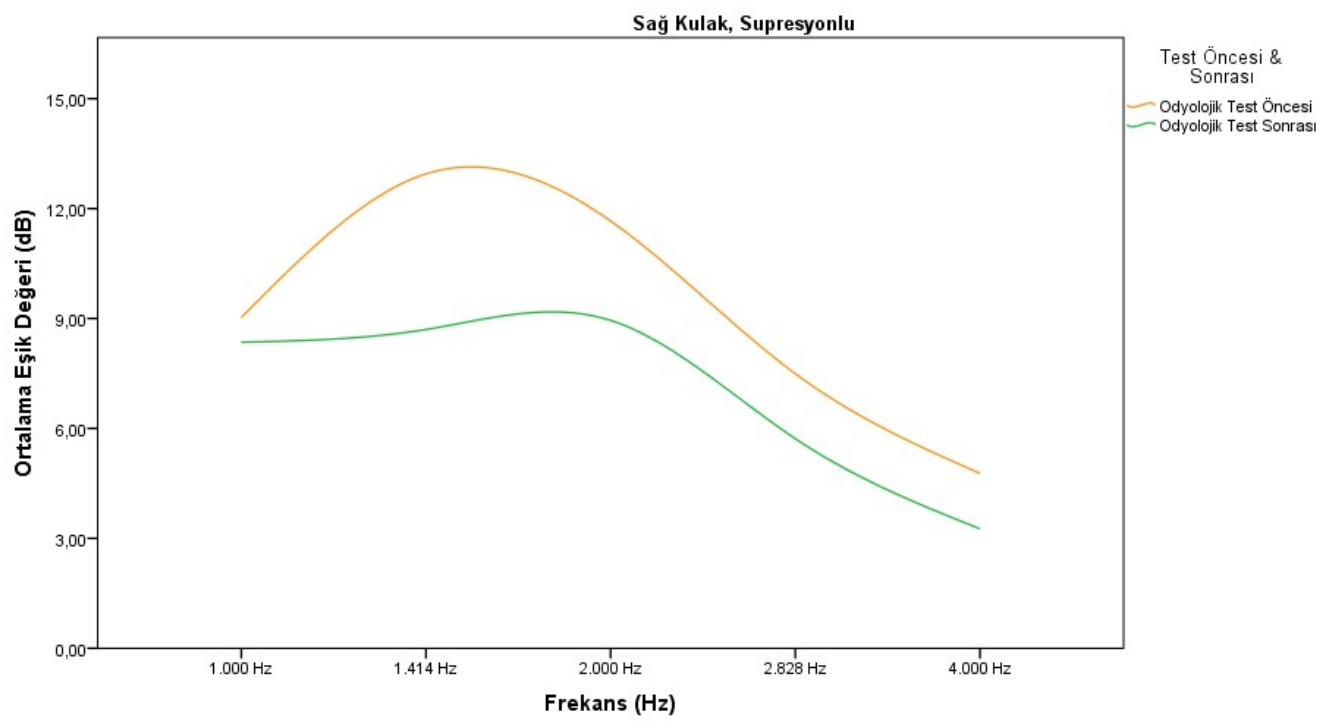

Figure 1: Line chart displaying the suppression values in the right ear

It was observed that the mean threshold values increased up to a frequency value of $1414 \mathrm{~Hz}$ before the audiological test, and decreased after reaching this frequency value. After the audiological test, the mean threshold values increased up to a frequency value of $2000 \mathrm{~Hz}$, and decreased after reaching this frequency value (Figure 1).

Wilcoxon signed-rank test was used for determining whether there was a significant difference between the threshold values of the left ear before and after the audiological test. Minimum, maximum, mean and standard deviation values were calculated for the threshold values before and after the test.

Table 2: Suppression Values of the Left Ear

\begin{tabular}{lllll}
\hline $\begin{array}{l}\text { Frequency } \\
\text { Value }\end{array}$ & $\begin{array}{l}\text { Before the Audiology Test } \\
\text { Mean } \pm \text { sd (Min - Max) }\end{array}$ & After the Audiology Test & Difference & $\begin{array}{l}\text { Test** } \\
\text { p Value } \pm \text { sd (Min - Max) }\end{array}$ \\
\hline $\mathbf{1 0 0 0 ~ H z}$ & $7.99 \pm 6.18(-4.00-17.10)$ & $5.23 \pm 5.72(-6.90-15.00)$ & $2.76 \mathrm{~dB}$ & 0.112 \\
$\mathbf{1 4 1 4} \mathbf{~ H z}$ & $11.05 \pm 5.44(2.40-22.60)$ & $7.24 \pm 5.20(1.00-16.20)$ & $3.81 \mathrm{~dB}$ & $\mathbf{0 . 0 0 6 *}$ \\
$\mathbf{2 0 0 0 ~} \mathbf{~ H z}$ & $10.06 \pm 7.59(-3.40-24.80)$ & $6.90 \pm 6.48(-5.60-19.60)$ & $3.16 \mathrm{~dB}$ & $\mathbf{0 . 0 0 6 *}$ \\
$\mathbf{2 8 2 8} \mathbf{~ H z}$ & $6.45 \pm 7.84(-4.60-22.60)$ & $4.85 \pm 5.44(-3.60-14.90)$ & $1.60 \mathrm{~dB}$ & 0.211 \\
$\mathbf{4 0 0 0 ~} \mathbf{~ H z}$ & $5.25 \pm 6.13(-4.00-14.90)$ & $4.01 \pm 5.90(-5.30-12.90)$ & $1.24 \mathrm{~dB}$ & 0.069 \\
\hline
\end{tabular}

sd: standard deviation; Min: lowest frequency value; Max: Highest Frequency value; **: Wilcoxon Signed-Rank Test; ${ }^{*} \mathrm{p}<0.05$ : There is a statistically significant difference between measurements. 
In the left ear, there was a decrease in the mean threshold values at frequencies of $1000 \mathrm{~Hz}, 2828 \mathrm{~Hz}$ and 4000 $\mathrm{Hz}$ after the audiological test. The changes in the mean threshold values at frequencies of $1000 \mathrm{~Hz}, 2828 \mathrm{~Hz}$ and $4000 \mathrm{~Hz}$ in the left ear were not found to be statistically significant ( $\mathrm{p}>0.05$, Table 2$)$.

In the left ear, mean threshold values at frequencies of $1414 \mathrm{~Hz}$ and $2000 \mathrm{~Hz}$ decreased after the audiological test. The changes in the mean threshold values in the left ear at frequencies of $1414 \mathrm{~Hz}$ and $2000 \mathrm{~Hz}$ were found to be statistically significant ( $\mathrm{p}<0.05$, Table 2 ).

The chart below displays the mean threshold values of the left ear. Frequency values are presented horizontally, and the mean threshold values are presented vertically. The orange line indicates the values before the audiological test, and the green line indicates the values after the audiological test.

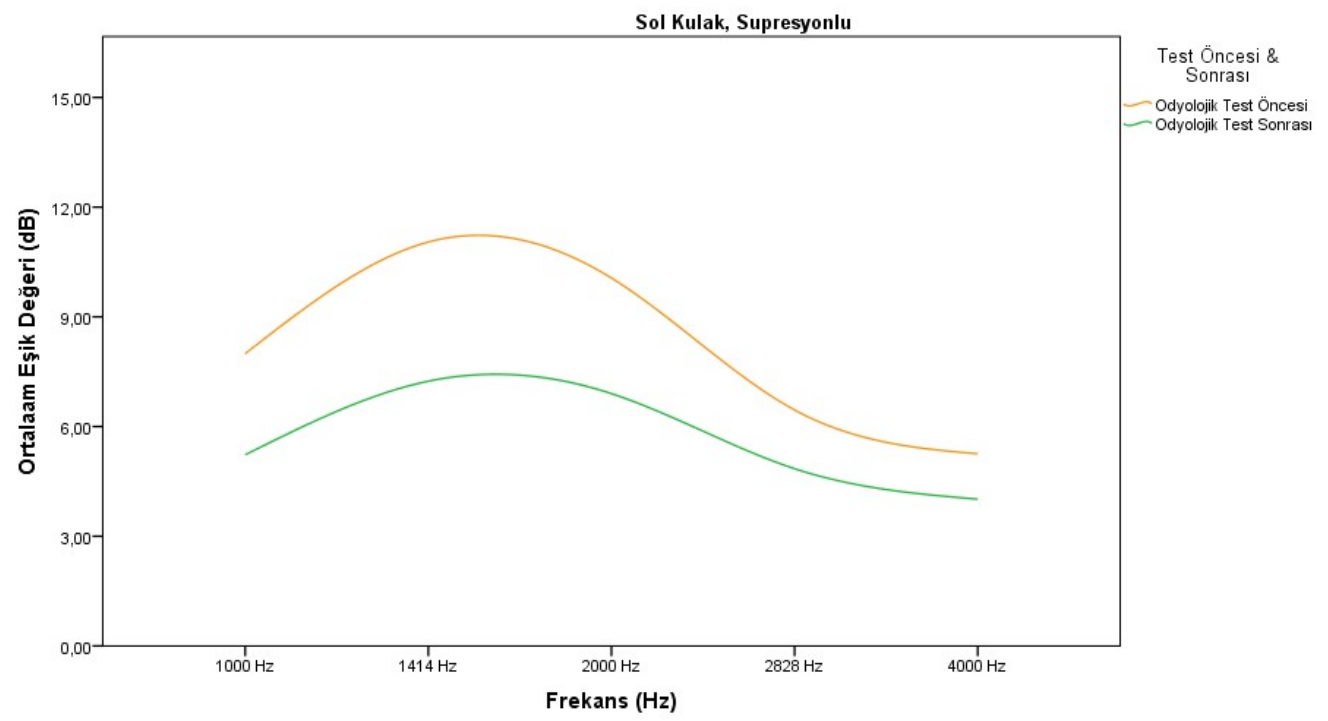

Figure 2: Line chart displaying the suppression values in the left ear

It was observed that the mean threshold values increased up to the frequency value of $1414 \mathrm{~Hz}$ before and after the audiological test, and decreased after this frequency value (Figure 2).

\section{Discussion}

In this study, we aimed to evaluate the efferent auditory systems in the right and left ears of individuals with normal hearing using contralateral acoustic stimulation test after audiological testing.

Various techniques are used for evaluating brain functions of the neural region within the Central Nervous System. The contralateral suppression test is one of the objective techniques used in the assessment of the auditory condition in the brain functions of the nervous system. Today, contralateral suppression and the efferent pathways of the central nervous system are examined and inquired by the studies.

Studies conducted between individuals with normal hearing and groups with auditory pathology have reported the TEOAE responses as higher emission responses in individuals with normal hearing. It has been noted that the difference in TEOAE amplitudes between the right and left ears is due to the difference in the number of OHCs; and the high TEOAE amplitudes in the right ear has been mentioned as the advantage of the peripheral right ear. (Joseph, 2008; David T Kemp, 2002)

The literature contains studies comparing the measurements of inter-aural emission. In his study, Kemp (2002) reported that the OAE amplitudes between the two ears of individuals with normal hearing could be different, and their values were close to each other (David T Kemp, 2002).

Dikbaş (2009) compared the amplitude values before suppression (1000-1414-2828-4000) between the control group and the experiment group, and reported that there was no significant difference between the two groups in terms of emission amplitudes at all frequencies (Dikbaş, 2009).

In the study conducted by Kaya (2015) on 40 individuals with normal hearing and bilateral tinnitus in terms of the age factor, the amplitudes of suppression were observed to have decreased with age; however there was no statistically significant difference. Our study had similar characteristics with the studies conducted by Kemp (2002) and Kaya (2015) (David T Kemp, 2002). 
Suppression has been defined as the decrease in otoacoustic emission amplitudes recorded by the introduction of an ipsilateral and contralateral sound to the ear with normal hearing. The characteristic impact of stimulating the efferent system by sending a contralateral signal is the suppression of OHCs, and it is determined as a decrease in the amplitude obtained for OAE. Suppression occurs within the efferent auditory system. The absence of suppression is a pathological condition that indicates dysfunction of the efferent auditory system (Hall, 2000).

In our study, the mean threshold values of the right and left ear at $1414 \mathrm{~Hz}$ and $2000 \mathrm{~Hz}$ after suppression decreased before and after the audiological test. The increase in the frequencies was found to be statistically significant $(\mathrm{p}<0.05)$.

Among the studies in the literature, the study conducted by Brashears et al. (2003) with the members of Louisiana Philharmonic Orchestra and 28 non-musicians on the difference in contralateral suppression in the right and left ears, findings regarding otoacoustic emission were compared in the presence of contralateral suppression. As a result, significantly higher suppression values were observed in the right ear compared to the left ear (Brashears, Morlet, Berlin, \& Hood, 2003).

Bar-Haim et al. (2004) compared 16 children with selective mutism and 16 healthy children using contralateral suppression. The selective mutism group had low TEOAE suppression in the right ear compared to the control group; however, they did not reach any significant conclusion regarding the left ear (Bar-Haim et al., 2004).

In a study on individuals with normal hearing and unilateral SPOAEs, Oysu et al. (2001) reported that the stimulation of the medial olivocochlear fibers caused a decrease in SPOAE amplitudes, and an increase in frequencies, similar to our study. (Oysu, Külekçi, \& Kavak, 2001)

Veuillet et al. concluded that there was a decrease in SPOAE amplitudes when they stimulated the ear with an unfiltered click ((Veuillet, Khalfa, \& Collet, 1999)). Likewise, Collet et al. reported that they observed similar decreases in TEOAE amplitudes.

In our study, while the mean threshold value of the right ear after suppression at the frequency of $4000 \mathrm{~Hz}$ was $4.77 \mathrm{~dB}$ before the audiology test, the mean threshold value of the right ear after suppression at $1414 \mathrm{~Hz}$ was $12.95 \mathrm{~dB}$; and the difference was statistically significant $(\mathrm{p}<0.05)$. While the mean threshold value of the right ear after suppression at the frequency of $4000 \mathrm{~Hz}$ was $4.77 \mathrm{~dB}$ before the audiology test, the mean threshold value of the right ear after suppression at $2000 \mathrm{~Hz}$ was $11.66 \mathrm{~dB}$; and the difference was statistically significant $(\mathrm{p}<0.05)$.

It has been reported that otoacoustic emission is used in the evaluation of cochlear functions in normal hearing, while contralateral suppression measurements are primarily and effectively used in evaluating retrocochlear pathology. In our study, the difference between hearing thresholds at $1414-2000 \mathrm{~Hz}$ before and after the test was found to be statistically significant in the audiological evaluation of the right ear with suppression $(p<0.5)$. On the other hand, the difference between the thresholds of the left ear before and after the suppression test was not statistically significant $(\mathrm{p}>0.05)$. Nonetheless, frequency values with suppression in the right and left ears have similar characteristics.

In his study, Karabulut (2009) found no significant difference between the patients with Type II Diabetes Mellitus (DM) and the control group in the contralateral suppression test. The pathological effects of Type II DM on the auditory system are predominantly at the cochlear level, affecting the functions of the outer hair cell. In this study, there was no data indicating that the MOC system was affected in Type II DM (Karabulut et al., 2014; Ren et al., 2009).

Suppression was statistically higher in full-term infants compared to the preterm infants. The maturation of the MOC system is completed at birth in humans, and it can be assessed using the OAE tests. The MOC system with good peripheral hearing sensitivity starts to regress from middle age. The loss of efferent control in outer hair cells due to aging can cause hearing loss and loss of peripheral right ear advantage (Ren et al., 2009).

Castor et al. (1994) reported that the amount of suppression obtained with exposure to contralateral acoustic stimulus decreased with age in 60 people with normal hearing and the elderly group ( 22 people between 70 and 88 years of age). In addition, they stated that there was more suppression and it was maintained better at $1-2 \mathrm{k} \mathrm{Hz}$ compared to 4-6kHz (Castor, Veuillet, Morgon, \& Collet, 1994).

In his animal study, Jacobson (2003) stated that the reduction of the functional effect of the MOC system against white noise could be observed primarily with the degeneration of outer hair cells; and this reduction in contralateral suppression conformed to the human studies. He stated that this loss of suppressive function could play an important role in the development of presbycusis (Jacobson, Kim, Romney, Zhu, \& Frisina, 2003).

Williams et al. (1993) reported continued uncompensated labyrinth disorder and subsequent vertigo attacks for 7 years in a 43-year-old female patient. Left vestibular neurectomy (cutting of vestibular nerve fibers) was performed. These fibers carry medial and lateral efferent fibers (Williams, Brookes, \& Prasher, 1993). The 
surgery eliminated the lack of inhibition, and efferent control of the receptor cells in the ear. The cutting of the olivocochlear bundle in the vestibular nerve led to the elimination of suppression in the operated side. Suppression occurred on the healthy side (Wagner, Frey, Heppelmann, Plontke, \& Zenner, 2008).

In the study by Muchnik (2004), which examined the speech disorders, it was reported that there were differences in brain function dominance between healthy individuals and patients with speech disorders such as stuttering; it was found that the right lobe of the brain was active while speaking in individuals with fluency disorder. In his study, Corballis (2009) determined the effects of the symptoms of cerebral asymmetry genetics on the brain in adults using imaging methods. Reversed left-right asymmetry and a decrease was observed in the white matter in the left brain hemispheres of the individuals with fluency disorder compared to the healthy individuals. Similarly, in their study on stuttering, Maguire et al. (2o12) reported that brain functions affected the right and left hemispheres differently (Maguire, Yeh, \& Ito, 2012).

Considering the anatomy and physiology of the central nervous, it is known that the right and left hemispheres of the brain operated in the cross direction. This was also confirmed with the findings of our study. Based on our study, we can argue that the otoacoustic emissions obtained in the right cochlea are affected by the left hemisphere, as stated in the literature.

In the study by Chang et al. (2008), where the differences in the anatomy of the brain regarding stuttering were investigated using imaging methods, they argued that the auditory cortex would be affected by the Medial Olivocochlear (MOC) system function, which would reflect on the auditory process (Chang, Erickson, Ambrose, Hasegawa-Johnson, \& Ludlow, 2008).

In a study in the literature that was conducted on children and adults with autism, the amplitude and suppression of TEOAE were found to be significantly higher in the right ear in all age groups (Khalfa 2001). In general, researchers suggest that the primary and secondary cortex have direct or indirect effects on the auditory system.

The differences in the threshold values and frequencies in both ears were not statistically significant in our study. This suggests that the auditory cortex creates a difference by affecting the structures of the upper brain.

As a result of the MOCR evaluation performed before and after the audiological test, the contralateral acoustic reflexes in both ears at 1414 and $2000 \mathrm{~Hz}$ were found to be statistically significant, and it was observed that the efferent system maintained its effectiveness at these frequencies against tone burst stimuli. The efficiency of the efferent system was also observed at other frequencies, which were found to be statistically insignificant. It is believed that this could be due to the insufficient sample size, which was a limitation of our study.

In order for the suppressive effect to be observed, the integrity of the neural structures must be preserved from the medial nucleus of the superior olivary complex until the OHCs. Looking at the results of our study, we can conclude that MOCR is active and the central nervous system has not been impaired after audiological evaluation. On the other hand, it is believed that a further study should be conducted with a larger sample group in order to obtain more specific results.

\section{References}

Bar-Haim, Y., Henkin, Y., Ari-Even-Roth, D., Tetin-Schneider, S., Hildesheimer, M., \& Muchnik, C. (2004). Reduced auditory efferent activity in childhood selective mutism. Biological psychiatry, 55(11), 10611068.

Brashears, S. M., Morlet, T. G., Berlin, C. I., \& Hood, L. J. (2003). Olivocochlear efferent suppression in classical musicians. Journal of the American Academy of Audiology, 14(6), 314-324.

Castor, X., Veuillet, E., Morgon, A., \& Collet, L. (1994). Influence of aging on active cochlear micromechanical properties and on the medial olivocochlear system in humans. Hearing research, 77(1-2), 1-8.

Chang, S.-E., Erickson, K. I., Ambrose, N. G., Hasegawa-Johnson, M. A., \& Ludlow, C. L. (2008). Brain anatomy differences in childhood stuttering. Neuroimage, 39(3), 1333-1344.

Dikbaş, M. (2009). Tinnituslu bireylerde otoakustik emisyon ile kontralateral supresyon mekanizmasının incelenmesi. DEÜ Sağlık Bilimleri Enstitüsü,

ER TOPRAK, S. (2016). Benign Paroksismal Pozisyonel Vertigoda Vestibüler Uyarılmış Myojenik Potansiyel (VEMP) ve Video Head Impuls (VHIT) Test Bulguları. Ankara Yıldırım Beyazıt Üniversitesi Sağlık Bilimleri Enstitüsü,

Hall, J. W. (2000). Handbook of otoacoustic emissions: Cengage Learning.

Jacobson, M., Kim, S., Romney, J., Zhu, X., \& Frisina, R. D. (2003). Contralateral suppression of distortion-product otoacoustic emissions declines with age: A comparison of findings in CBA mice with human listeners. The Laryngoscope, 113(10), 1707-1713.

Joseph, B. (2008). Relationship among otoacoustic emission suppression and auditory processing measures in adults. 
Karabulut, H., Karabulut, I., Dağli, M., Bayazit, Y. A., BİLEN, Ş., Aydin, Y., . . . Bayramoğlu, I. (2014). Evaluation of outer hair cell function and medial olivocochlear efferent system in patients with type II diabetes mellitus. Turkish journal of medical sciences, 44(1), 150-156.

Kemp, D. T. (1978). Stimulated acoustic emissions from within the human auditory system. J Acoust Soc Am, 64(5), 1386-1391. doi:10.1121/1.382104

Kemp, D. T. (2002). Otoacoustic emissions, their origin in cochlear function, and use. British medical bulletin, 63(1), 223-241.

Maguire, G. A., Yeh, C. Y., \& Ito, B. S. (2012). Overview of the diagnosis and treatment of stuttering. Journal of Experimental \& Clinical Medicine, 4(2), 92-97.

Oysu, Ç., Külekçi, M., \& Kavak, L. (2001). Kontralateral Akustik Uyar»n〉 n Spontan Otoakustik Emisyonlar Üzerine Etkileri.

Ren, J., Zhao, P., Chen, L., Xu, A., Brown, S. N., \& Xiao, X. (2009). Hearing loss in middle-aged subjects with type 2 diabetes mellitus. Archives of medical research, 40(1), 18-23.

Smith, S. B., \& Cone, B. (2015). The medial olivocochlear reflex in children during active listening. Int J Audiol, 54(8), 518-523. doi:10.3109/14992027.2015.1008105

Veuillet, E., Khalfa, S., \& Collet, L. (1999). Clinical relevance of medial efferent auditory pathways. Scandinavian Audiology. Supplementum, 51, 53-62.

Wagner, W., Frey, K., Heppelmann, G., Plontke, S. K., \& Zenner, H.-P. (2008). Speech-in-noise intelligibility does not correlate with efferent olivocochlear reflex in humans with normal hearing. Acta otolaryngologica, 128(1), 53-60.

Williams, E. A., Brookes, G. B., \& Prasher, D. K. (1993). Effects of contralateral acoustic stimulation on otoacoustic emissions following vestibular neurectomy. Scandinavian audiology, 22(3), 197-203. 